\title{
U.S. Geological Survey Disaster Response and the International Charter 'Space and Major Disasters'
}

In 1999, an international consortium of space agencies conceived and approved a mechanism to provide satellite information in support of worldwide disaster relief. This group came to be known as the International Charter 'Space and Major Disasters' ("Charter") and has become an important resource for the use of satellite data to provide response support for natural and man-made disasters. From the Charter's formative days in 1999, its membership has expanded to 15 organizations managing a large constellation of Earth-observing satellites.

The Charter was activated for the first time in November 2000 when a major landslide occurred in Slovenia. Original Charter members, the French Space Agency (CNES), the European Space Agency (ESA), and the Canadian Space

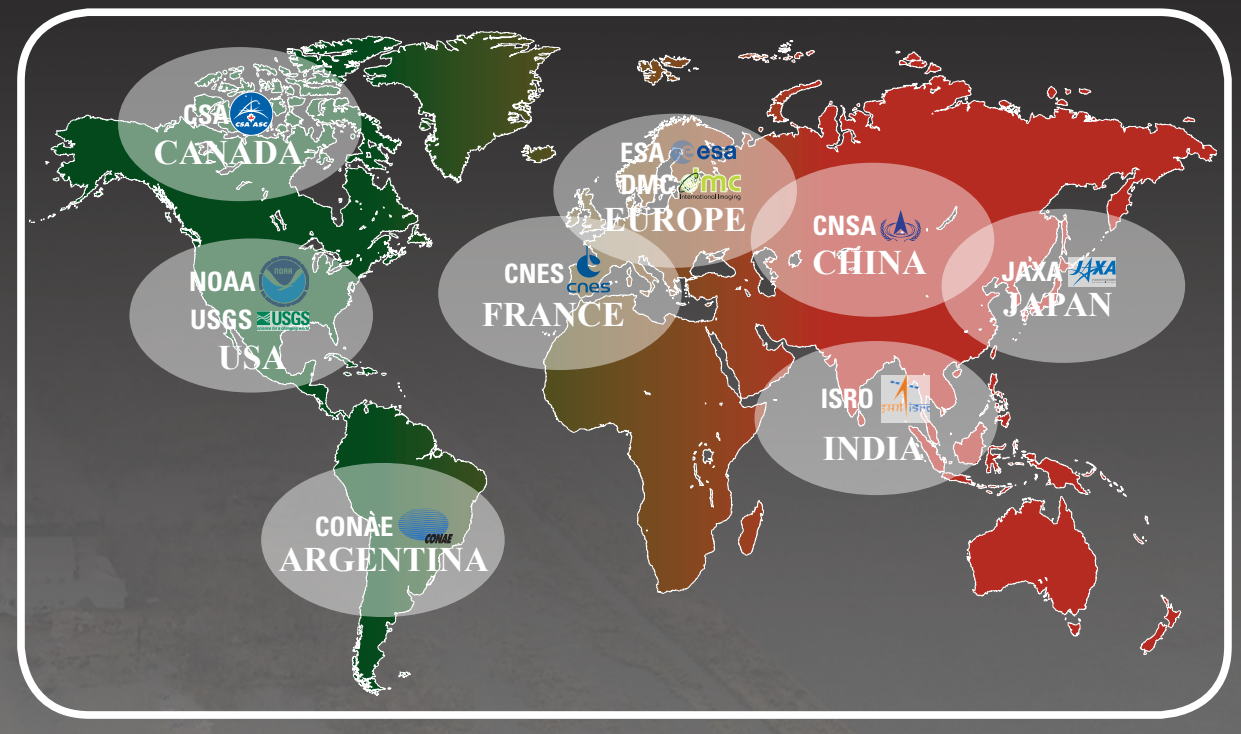

Charter Member Agencies

Agency (CSA), provided optical and radar satellite data to map the extent of the damage caused by the landslide. Since that time, the Charter has been activated hundreds of times in response to natural disasters such as earthquakes, landslides, volcanic eruptions, floods, hurricanes, fires, and technological disasters such as oil spills.

Charter members respond quickly when called upon by national emergency management authorities. Satellite data are made available at no cost to the emergency managers, as the Charter operates on a voluntary basis with

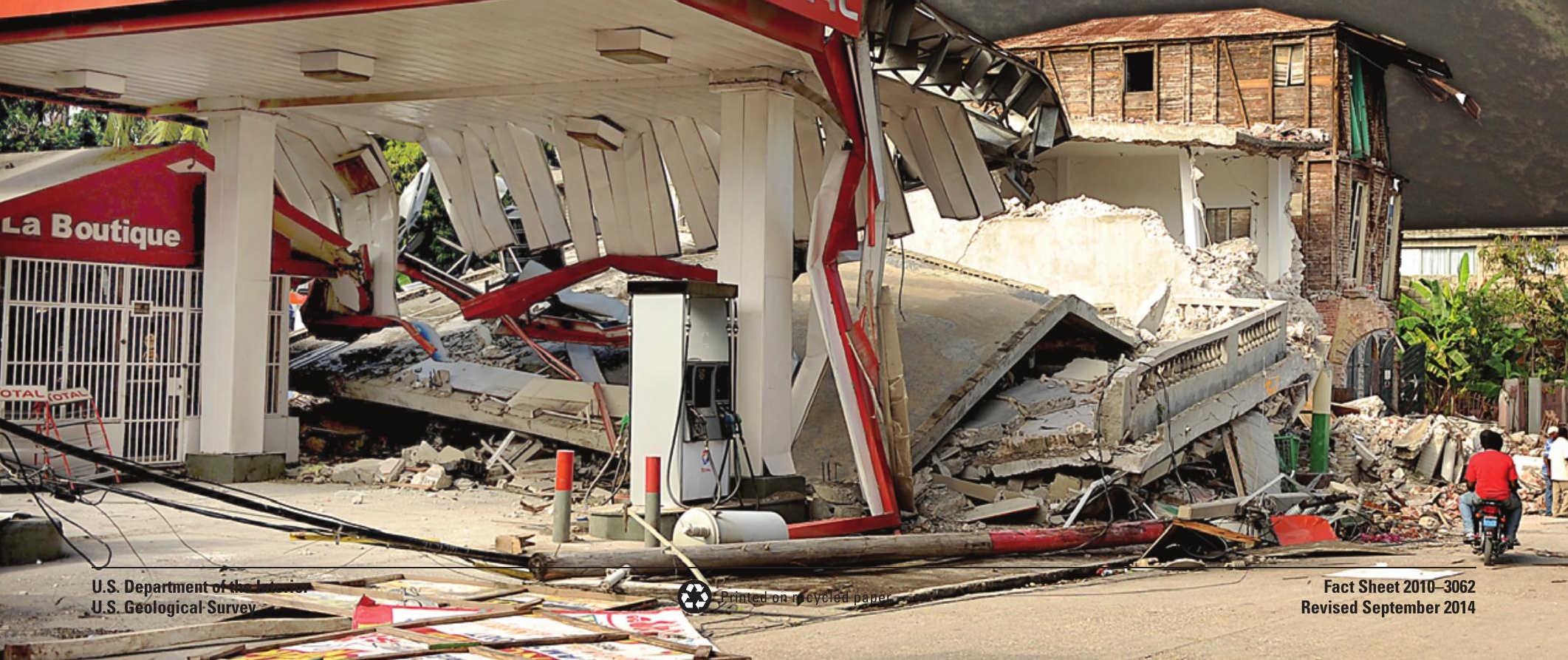


no exchange of funds. The data from the Charter-managed satellites have helped emergency managers worldwide deal with a variety of natural and technological disasters. When disasters endanger human life, the imagery provided by member agencies can provide valuable insight into the extent and impact of the disaster event.

More specifically, when a major event is imminent or has happened and relief and reconstruction efforts are anticipated, Charter members respond with multi-satellite data acquisition planning, archive retrieval capabilities, and high-priority spacecraft tasking.

The U.S. Geological Survey (USGS) is an active participant, drawing on government and commercial data sources to support Charter needs. Extensive USGS historical and current satellite data have proven useful to disaster management agencies, international relief organizations, and the science community at large.

Effective operational procedures ensure that information is delivered to emergency responders in a timely manner. On-duty operators and

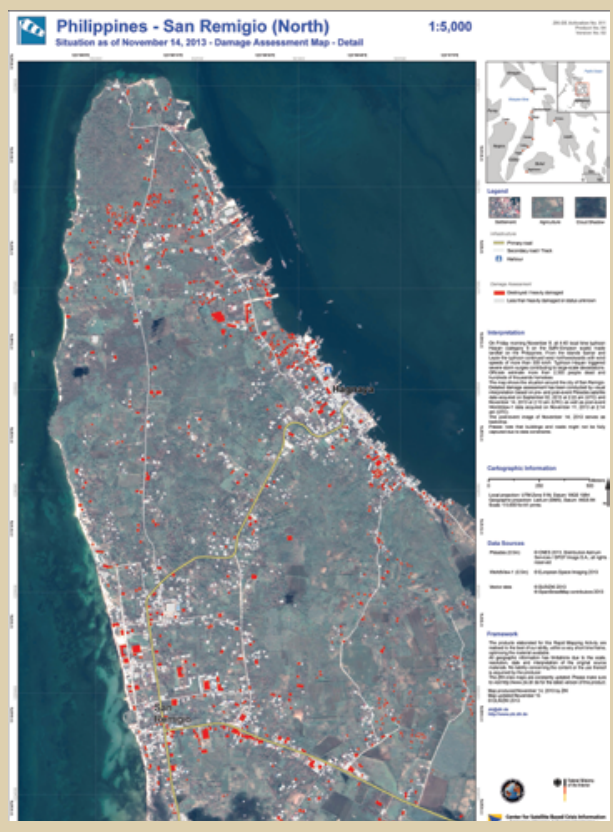

Example Charter damage assessment map product for the 2013 Typhoon Haiyan response in the Philippines. (Mapping and analysis by German Aerospace Center [DLR], based on imagery provided by Centre National d'Etudes Spatiales [CNES])

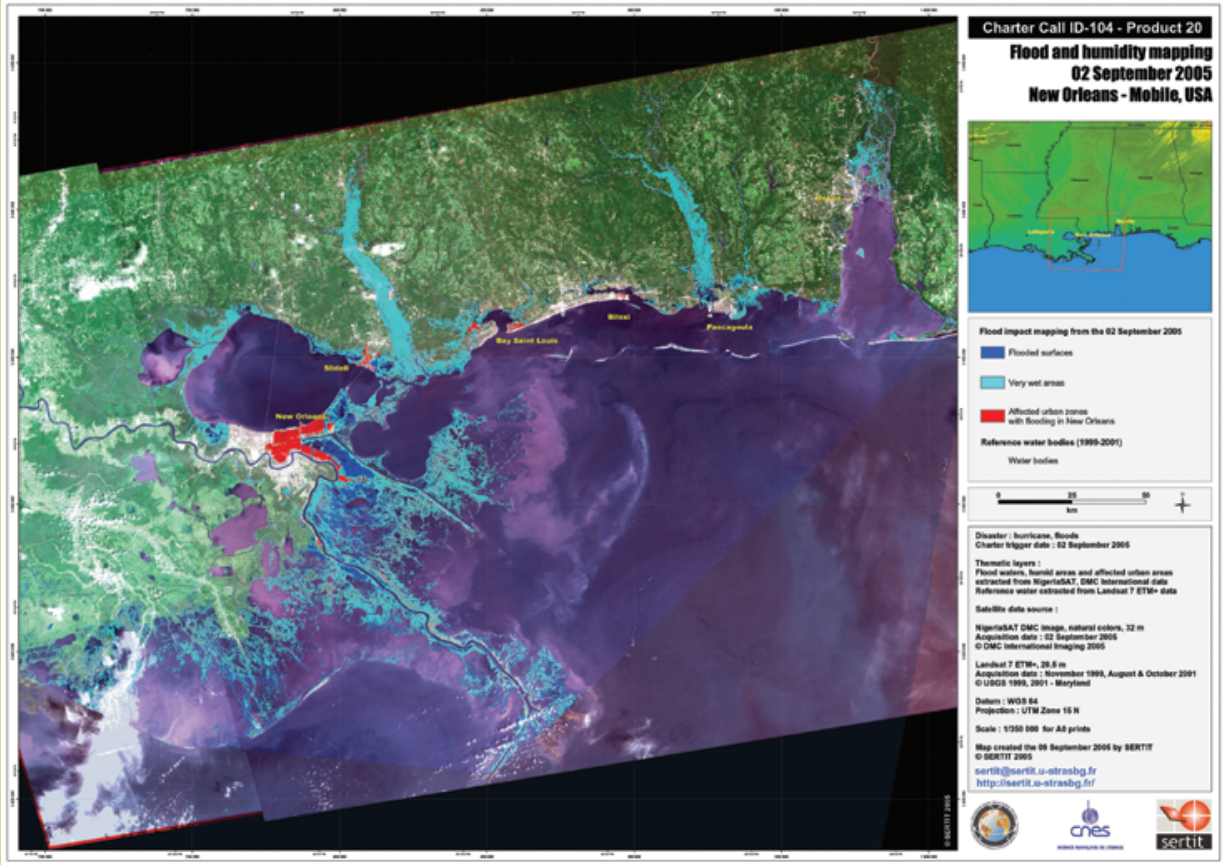

Example Charter flood inundation map product for the 2005 Hurricane Katrina response. (Mapping and analysis by Service Régional de Traitement d'Image et de Télédétection [SERTIT], based on imagery provided by Disaster Monitoring Constellation International Imaging [DMCii] and USGS)

emergency on-call officers are available $24 / 7$ to receive and process requests for relevant satellite data. Charter members quickly assess the severity of particular disasters and the relevancy of satellite data holdings and capabilities. Satellite image acquisition plans are developed and evaluated, and the appropriate agencies are contacted to confirm the details.

The success of the International Charter is demonstrated through its continued use by a growing number of emergency authorities worldwide. As an important step in its continued evolution, the Charter implemented a policy of Universal Access in 2012. This policy provides expanded access to national users who previously were unable to make direct requests to the Charter during emergency situations. The provision of Universal Access allows any national disaster management authority to submit a request for emergency response image support directly to the Charter. Proper procedures will need to be followed, but the affected country does not have to be a Charter member. A registration process was established to allow national authorities to express interest in participating in the Charter. This policy will benefit national users in countries who were previously unable to make direct requests to the Charter detailed information on Universal Access and the registration process, see the Charter website (http://www. disasterscharter.org/web/charter/ activate). during emergency situations. For

\section{Information}

For more details regarding the International Charter, additional example map products that members have provided, and more information on Universal Access, please see http://www.disasterscharter.org/. 